\title{
APLICAÇÃO DA ESTIMULAÇÃO ESSENCIAL À CRIANÇA HOSPITALIZADA
}

\author{
Ivone Evangelista Cabral*
}

RESUMO - O trabalho apresenta uma proposta de atendimento de enfermagem à criança hospitalizada, cujo objetivo principal é a promoção da reabilitação física, mental e social para aqueles que apresentarem retardo no desenvolvimento psico-motor, na faixa etária de 30 dias a 2 anos de idade.

\begin{abstract}
This papers presents a purpose of attending of nursing, to hospitalized children with more of thirty days old until two years old, that they has shown up lack of stimulation and development later. For these groups it has aplicated a special stimulation sighting a physical, psychological and social recuperation.
\end{abstract}

\section{INTRODUÇÃO}

A Estimulação Essencial ao Desenvolvimento, constitui uma necessidade humana básica para um crescimento e desenvolvimento harmônico, pois através desta prática, a criança desenvolve o seu potencial genético e atinge a maturidade física, mental e social.

Em contrapartida, o processo de hospitalização determina um comportamento regressivo na criança, além de provocar uma parada ou retardamento no desenvolvimento das potencialidades.

Baseado nestas duas situações, é que tem se processado a aplicação da estimulação essencial em um grupo de crianças hospitalizadas, que permanece sob os cuidados profissionais da autora, numa enfermaria de lactentes.

\section{ESTIMULAÇÃO ESSENCIAL: ASPECTOS GERAIS}

O termo Estimulação Essencial foi introduzido, primeiramente, pela educadora MARINHO (1978), partindo de um conceito próprio, de acordo com sua longa experiência. Segundo esta autora, no que diz respeito ao desenvolvimento e a educação, nada pode ser feito "antes do tempo", portanto, a tradução Estimulação Precoce não se aplica à nossa língua. A expressão original é "Early Estimulation" ou "Estimulación Temprana". Continua a autora, afirmando que a Estimulação é Essencial, já que assume o papel de importante incentivador do meio no processo evolutivo da criança.

CRAVIOTO \& MIL L ÁN (9184) destacam a importância do ambiente estimulante e rico em experiências, pois segundo eles, ambientes desfavoráveis reduzem a capacidade de desenvolvimento mental das crianças, ainda que, tal capacidade já esteja geneticamente programada.

Vários autores concordam que o máximo de crescimento e desenvolvimento cerebral se dá até o 30 ano de vida estendendo-se ao 6으.

Crianças com privação nutricional apresentam acentuado retardo no desenvolvimento. Vários estudos têm demonstrado que à medida que se dá a recuperação nutricional, os quocientes de desenvolvimento também aumentam, de acordo com a idade cronológica da criança. Desde que estas recebam, associadas ao tratamento clínico-nutricional, um programa sistemático de Estimulação Essencial, com a participação da família ("interación madre-hijo").

TEIXEIRA (1984) lembra que as Instituições: Assistenciais fechadas (orfanatos, hospitais, creches, etc.) que normalmente são pobres de ambientes, precisam se reestruturarem para que não comprometam o desenvolvimento e a intelectualidade da criança.

Portanto, a aceitação da criança, o apoio afetivo, o ambiente rico e variado de estímulos, adequados à etapa evolutiva, somando-se a participação real dos adultos são essenciais ao desenvolvimento.

Além disto, os Hospitais, destaca NASCIMENTO (1984) tratam a criança e a alimentam em ambientes monótonos, tristes, sem brinquedo, sem calor humano, privados de experiências e longe de seu ambiente familiar. Estes fatores determinam atraso de desenvolvimento se este período é prolongado, e por vezes determina a Síndrome do Hospitalismo, descrita por SPITZ (1964).

LOPEZ et alii (1987) afirmam que crianças freqüentemente são re-hospitalizadas seja por patologias crônicas ou desnutrição, durante o período de seu desenvolvimento mais vulnerável à separação de sua família, contar: ainda como agravante, que os hospitais não dispõem de recursos humanos adequados para diminuir ou evitar o impacto que estes episódios podem causar no desenvolvimento.

De acordo com o exposto acima, não se pode deixar de considerar a Estimulação Essencial à criança, como sendo uma das necessidades humanas básicas, ao lado da necessidade de nutrição, oxigeração, elimiração, amor e segıı ança emocional, etc., definidas por MASLOW.

Através do lúdico a criança descobre c mundo, estimula a criatividacie e a coordenação sensório-motora e a percepção, além de preparaŕ-se para a vida adulta.

\section{AVALIAÇÃO DA IDADE DE DESE NVOLVIMENTO}

A Escala de Desenvolvimento de MARINHO (1978) consiste na organização de provas em dois sentidos:

- vertical, por idade $(1 ; 2+15$ - lê-se 1 ano; 2 meses + 15 dias);

* Enfermeira Pediatra-Rio de Janeiro. 
- transversal, em escala progressiva da evolução do comfcrtamento.

A escola das provas teve por objetivo a demonstração experimental da unidade do processo contínuo do desenvolvimenio físico, mental e social.

O total das provas positivas constitui a idade do desenvolvimento. O limite inferior da capacidade da criança é determinadc $+5)$. O limite superior é cieterminado por 5 provas negativas ( $\mathrm{LS}=-5)$.

Considera-se, quando mais lento o ritmo de desenvolvimento maior é o valor de cada prova.

\begin{tabular}{crl}
\hline IDADE & UMA PROVA & SEIS PROVAS \\
\hline $0 ; 0$ a $007+29$ & $5 \mathrm{~d}$ & $30 \mathrm{~d}=1$ mês \\
$0 ; 8$ a $0 ; 11+29$ & $10 \mathrm{~d}$ & $60 \mathrm{~d}=2$ meses \\
$1 ; 0$ a $1 ; 5+29$ & $15 \mathrm{~d}$ & $90 \mathrm{~d}=3$ meses \\
$1 ; 6$ a $1 ; 11+29$ & $30 \mathrm{~d}$ & 6 meses \\
$2 ; 8$ a $3 ; 11$ & $2 \mathrm{~m}$ & 12 meses $=1$ ano \\
\hline
\end{tabular}

O Cálculo do Quociente de Desenvolvimento (QD) é feito, da seguinte maneira:

$$
\begin{aligned}
& \mathrm{QD}=\mathrm{ID}_{\mathrm{IC}}^{\mathrm{ID}} \times 100 \text {, considerando-se: } \\
& 90 \text { - Inferior } \\
& 90 \text { a } 110 \text { - Normal } \\
& 110 \text { - Superior }
\end{aligned}
$$

Outras informações devem ser acrescentadas ao relatório, para que se possa avaliar a idade de desenvolvimento da criança tais como:

- situação em que foram realizadas as provas;

- descrição do ambiente;

- relato dos fatos na ordem em que se apresentaram;

- registro da estimulação do ambiente (relação social e afetiva estabelecida entre a criança e a examinadora);

- relato completo das reações da criança e a linguagem após 1 ano e 1/2 de IC - incluir os desenhos.

Ao profissional que aplica a estimulação essencial, é indispensável:

- conhecimento do processo de desenvolvimento humano (normal e os desvios);

- bom observador;

- aceitação af etiva da criança;

- organização de ambientes estimuladores; vimento.

- estimular de acordo com a etapa de desenvol-

\section{FATORES QUE DETERMINAM A CLASSIFICAÇÃO E SELEÇÃO DAS ATIVIDADES LÚDICAS}

BARRETO (1979) - O brinquedo tem finalidade recreativa e estimuladora do desenvolvimento físico, mental e social da criança. Portanto, devemos evitar os seguintes erros:

- excesso de brinquedos;

- brinquedos perfeitos demais;

- brinquedos completos demais para a capacida- de de compreensão e utilização da criança naquela idade.

Geralmente, elas brincam de preferência com caixas de papelão, pedaços de papel ou tubos de plásticos.

As atividades recreativas devem ser compatíveis com o estágio de desenvolvimento inf antil.

\section{MÉTODO DESENVOLVIDO}

A avaliação do desenvolvimento das crianças que participam do programa de Estimulação é feita através da Escala de Desenvolvimento de MARINHO (1978) e se dá em 3 etapas:

Primeira etapa - Após estabelecimento de um Rapport com a criança. Quando demonstra sinais de recuperação clínicas.

Segunda etapa - Na alta hospitalar.

Terceira etapa - Na primeira consulta ambulatorial pós-alta. somente para o grupo que tem um $C D$ $\leqslant 90 \%$.

\section{MATERIAL UTILIZADO}

As práticas estimuladoras programadas, estão de acordo com a idade de desenvolvimento da criança, apuradas pela aplicação da Escala de MARINHO (1978) e reformuladas à medida que novas habilidades são adquiridas.

O material utilizado viria desde a sucata hospitalar, jogos de repetição, exercícios para fortalecimento da musculatura, preparo para aquisição dos hábitos de vida diária etc., além da ef etiva participação da família através do acompanhamento pelo responsável.

\section{Material utilizado no Programa:}

a. uso de material de sucata hospitalar que favoreçam a aceitação do tratamento (rolo de esparadrapo, seringa descartável, equipo de soro, frasco de soro...);

b. uso de brinquedos simples, laváveis e coloridos (chocalho, peteca, bonecos maleáveis, carrinho, patinho, etc.);

c. estímulo a deambulação atravếs de exercícios passivos e ativos, ajuda na deambulação (apoiando sob os ombros);

d. muito calor humano, passeios ao ar livre, uso de roupas coloridas;

e. desenho com lápis de cera (avaliação da fase de rabiscação à fase celular);

f. uso da música;

g. ensino da linguagem;

h. estímulo a independência no se alimentar, hora do banho, vestir-se.

\section{PROGRAMA DESENVOLVIDO}

O programa de estimulação adotado, é aplicado à criança desde o primeiro dia de internação, ainda quando desconhecemos o seu $\mathrm{CD}$, apenas pelo levan- 
tamento do desenvolvimento pregresso colhido com a mãe no ato da internação. Este então, será ajustado, de acordo com as condições clínicas da criança.

Após aplicação da Escala, e constatado que o seu CD está entre 90 e 110, este não será mais avaliado.

\section{Resumo do Programa}

\section{PROGRAMA DE ESTIMUL AÇÃO}

PRIMEIRA FASE - MATERIAL HOSPITAL AR

Objetivo - favorecer a aceitação do tratamento e a hospitalização;

- verificar o grau de coordenação motora.

Objetos - rolo de esparadrapo, frasco de soro, microfix, tc.

\section{SEGUNDA FASE - BRINQUEDOS SIMPLES}

\section{LAVÁVEIS E COL ORIDOS}

Objetivo-promover estímulos visuais, táteis e sonoros.

Objetos - chocalho, peteca, bonecos maleáveis, móbiles, carrinhos etc.

TERCEIRA FASE - DEAMBUL AÇÃO, AQUISI . ÇÃO DE HVD - JOGOS INFANTIS

Objetivo - estimular a deambulação, desenvolver hábitos de vida diária.

Objetos - andar apoiado nas pessoas e objetos;

- exercícios ativos e passivos para desenvolver musculatura;

- deixar que se alimente com as próprias mãos;

- uso do espelho para aquisição de esquema corporal;

- música;

- lápis de cera para verificar lateralidade, tipo de linhas (contínuas, descontínuas, fase celular);

- estímulo ao desenvolvimento da linguagem.

\section{CONCLUSÃO}

Este trabalho vem sendo desenvolvido há dois anos nesta Instituição, e tem motivado vários profissionais a participarem do programa, com proposta de extensão às demais enfermarias e ambu htório. Além disto, 4 enfermeiros, inclusive a autora deste, realizaram um Curso de Especialização em Estimulação Essencial desenvolvido pela Escola de Enfermagem Ana Nery e Sociedade Pestalozzi do Brasil, no intuito de coordenadr um Programa de Estimulação de maior abrangência.

Durante este período, tivemos mais de 50 crianças que participaram do programa, com significativos ganhos de coeficiente de desenvolvimento e participação da família.

Vale ressaltar, que o programa adotado é flexível, e não obedece a nenhuma regra pré-estabelecida, sendo considerado como elemento básico a idade de desenvolvimento, a área de desenvolvimento mais afetada (física, mental e social) e a disponibilidade e a adequação dos recursos.

\section{REFERÊNCIAS BIBLIOGRÁFICAS}

1 BENATHAR, Roberto Levy. Desenvolvimento infantil em debate. Rio de Janeiro, INEPEDEC, 1984, p. 83-93, 198-220.

2 BOLETIM DA SOCIEDADE PESTALOZZI DO BRASIL. Recursos de Estimulação n 48/49, Rio de Janeiro, junho/1978.

3 ENFERMAGEM MODERNA. Rio de Janeiro, v. 3, n.2, abr/maio/jun. 1985.

4 LOPEZ et alii. Importância da reabilitação psicológica na desnutrição grave. Anais Nestlé, 43(1) fev. 1987.

5 MARINHO, Heloisa. Escala de desenvolvimento. Rio de Janeiro, Papelaria América, 1978.

6 . Currículo por atividades. 2. ed., Rio de Janeiro, Papelaria América, 1980.

7 QUADERNOS DE NUTRICIÓN. Desnutrición Y desarrollo mental. México, May/Jun. 1984.

8 RIZZO, Gilda. Creche - Organização, montagem e funcionamento. Rio de Janeiro, Francisco Alves, 1984. 